Article

\title{
A Peptidomimetic Fluorescent Probe to Detect the Trypsin $\beta 2$ Subunit of the Human 20S Proteasome
}

\author{
Magdalena Wysocka ${ }^{\dagger}$, Anita Romanowska ${ }^{\dagger}$, Natalia Gruba, Michalina Michalska, \\ Artur Giełdoń $(\mathbb{D}$ and Adam Lesner *(D) \\ Faculty of Chemistry, University of Gdansk, Ul. Wita Stwosza 63, 80-308 Gdansk, Poland; \\ magdalena.wysocka@ug.edu.pl (M.W.); anita_romanowska@o2.pl (A.R.); natalia.gruba@ug.edu.pl (N.G.); \\ michalinamichalska@icloud.com (M.M.); artur.gieldon@ug.edu.pl (A.G.) \\ * Correspondence: adam.lesner@ug.edu.pl; Tel.: +48-585-235-095; Fax: +48-585-235-472 \\ + These authors contributed equally to this work.
}

Received: 2 March 2020; Accepted: 29 March 2020; Published: 31 March 2020

\begin{abstract}
This work describes the chemical synthesis, combinatorial selection, and enzymatic evaluation of peptidomimetic fluorescent substrates specific for the trypsin-like ( $\beta 2$ ) subunit of the $20 S$ human proteasome. After deconvolution of a library comprising nearly 6000 compounds composed of peg substituted diaminopropionic acid DAPEG building blocks, the sequence ABZ-Dap $(\mathrm{O} 2(\mathrm{Cbz}))-\mathrm{Dap}(\mathrm{GO} 1)-\mathrm{Dap}(\mathrm{O} 2(\mathrm{Cbz}))-\mathrm{Arg}-\mathrm{ANB}-\mathrm{NH}_{2}$, where ABZ is 2-aminobenzoic acid, and ANB- 5 amino 2- nitro benzoic acid was selected. Its cleavage followed sigmoidal kinetics, characteristic for allosteric enzymes, with $K_{\mathrm{m}}=3.22 \pm 0.02 \mu \mathrm{M}, k_{\text {cat }}=245 \mathrm{~s}^{-1}$, and $k_{\text {cat }} / K_{\mathrm{m}}=$ $7.61 \times 10^{7} \mathrm{M}^{-1} \mathrm{~s}^{-1}$. This process was practically halted when a selective inhibitor of the $\beta 2$ subunit of the 20S human proteasome was supplemented to the reaction system. Titration of the substrate resulting in decreased amounts of proteasome $20 \mathrm{~S}$ produced a linear signal up to $10^{-11} \mathrm{M}$. Using this substrate, we detected human proteasome $20 \mathrm{~S}$ in human urine samples taken from the bladders of cancer patients. This observation could be useful for the noninvasive diagnosis of this severe disease.
\end{abstract}

Keywords: peptidomimetics; libraries; fluorogenic substrates; proteasome; bladder cancer

\section{Introduction}

The $20 \mathrm{~S}$ proteasome has a tube-like structure composed of four rings formed by 28 protein subunits [1,2]. The external rings are composed of seven distinct $\alpha$ subunits while the internal rings are composed of seven diverse $\beta$ subunits. All $\alpha$ subunits have structural functions, whereas only three of the $\beta$ subunits ( $\beta 1, \beta 2$, and $\beta 5$ ) have active centers (catalytic sites) [3]. In each of these $\beta$ subunits, a threonine (Thr) residue is positioned at the N-terminal. This amino acid is crucial for the proteolytic activity of the enzyme.

The cleavage specificity of each catalytically active $\beta$ subunit is defined by the structure of its $S 1$ binding pocket, particularly the chemical properties of the amino acid residue located at position 45 of the proteasome structure [4]. The $\beta 1$ subunit contains Arg at this position in the vicinity of the binding cleft, thereby accommodating and recognizing the acidic amino acids Glu and Asp and cleaving the peptide bond at the C-terminal side. At position 45 of the $\beta 2$ subunit, Gly cooperates with its neighbor Glu53, and accepts positively charged amino acid residues such as Lys and Arg. This assembly is referred to as trypsin-like activity. Lastly, the $\beta 5$ subunit, with Met45 in the substrate pocket $[5,6]$, cleaves peptide bonds on the carboxyl side of hydrophobic amino acids (aliphatic and aromatic).

Elevated 20S proteasome activity has been reported in several human diseases, including lupus erythematosus [7], rheumatoid arthritis [8], and various kinds of malignancies. For example, catalytic overexpression of the $20 \mathrm{~S}$ proteasome core has a diagnostic value in disease therapy [9]. 
The origin of its presence outside of the cell remains unclear, with two different hypotheses having been proposed. The first suggests that the presence of the $20 \mathrm{~S}$ proteasome is an effect of cell death by necrotic- or macrophage-mediated cytolysis. The second postulates that the $20 \mathrm{~S}$ proteasome is related to the abnormally fast division of cancer cells [7]. Proteasome 20S secreted outside the cell has the most significant diagnostic value and this form is referred to as the circulating proteasome. Its presence and associated increased enzymatic activity has been observed in several kinds of cancer, including breast tumors [10], prostate cancer [11], head and neck neoplasms [12], and ovarian cancer [7,13].

Common examples are patients with multiple myeloma, whose circular $20 \mathrm{~S}$ proteasome concentrations range between 1.81 and $11.06 \mu \mathrm{g} / \mathrm{mL}$. However, for healthy people, this value never exceeds $1 \mu \mathrm{g} / \mathrm{mL}[14,15]$; thus, to facilitate the development of a simple and robust proteasome assay, novel and sensitive tools to study proteasome activity are required.

The aim of this work is to develop a new substrate to assay the trypsin-like specificity of the human $20 \mathrm{~S}$ proteasome that is created by DAPEG building blocks, which are N-substituted functionalized derivates of 3-diaminopropionic acid (Figure 1). The substrate preferences of the $\beta 2$ subunit have been previously examined [16]. Harris and coworkers [17] described the development of new substrates selected via combinatorial library screening. The substrate peptides were labeled with 7-amino-4-carbamoylmethylcoumarin (ACC) as a reporter moiety, and a specific sequence of the $\beta 2$ subunit, Ac-Glu-Ala-Nle-Arg-ACC, was used to measure the $20 \mathrm{~S}$ proteasome activity [17]. Several substrates are currently available for measuring the trypsin-like activity of the proteasome: including commercially available $20 S$ proteasome substrates containing C-terminal 7-amino-4-methylocoumarin (AMC), which forms an amide bond with Arg, namely Ac-Leu-Arg-Arg-AMC and Boc-Leu-Arg-Arg-AMC. Both substrates display significant selectivity for measuring trypsin-like specificity. However, they display a low specificity constant of $10^{4} \mathrm{M}^{-1} \mathrm{~s}^{-1}$. Recently, Rut and co-workers applied a combinatorial chemistry approach and used positional scanning techniques to derive new selective substrates for the individual $20 \mathrm{~S}$ proteasome subunits $\beta 1, \beta 2$, and $\beta 5$. For the trypsin subunit, the most selective substrate sequence was Ac- $\beta$ Ala-Met $\left(\mathrm{O}_{2}\right)-\mathrm{Thr}-\mathrm{Arg}-\mathrm{ACC}$, which displayed moderate specificity parameters $\left(43,790 \mathrm{M}^{-1} \mathrm{~s}^{-1}\right)$. The most potent peptide in terms of specificity is the Ac-DArg-Hse-Thr-Arg-ACC $\left(301,005 \mathrm{M}^{-1} \mathrm{~s}^{-1}\right)$ peptide, which has moderate selectivity at higher proteasome concentrations [18].

Recently [19], we established a new method for the selection and synthesis of artificial fluorogenic substrates composed of DAPEG residues (Figure 1). For the screening of 18 libraries, we created a series of compounds based on the neutrophil serine protease 4 (NSP4) substrate sequence (ABZ-X4-X3-X2-Arg-ANB- $\mathrm{NH}_{2}$ ) diversified in positions $\mathrm{X} 4$ to $\mathrm{X} 2$ with DAPEG, resulting in a total of almost 6000 compounds. The compound ABZ-Dap(O2(Cbz))-Dap(Cbz)-Dap(GO1)-Arg-ANB- $\mathrm{NH}_{2}$ displayed high levels of selectivity towards neutrophil-related proteases and generated a specificity constant $\left(k_{\text {cat }} / K_{\mathrm{m}}\right)$ reaching $1.3 \times 10^{5} \mathrm{M}^{-1} \mathrm{~s}^{-1}$. Moreover, based on putative binding, the model substrate interacted with enzymes using secondary binding sites that were distant from the active center of the protease [19]. 


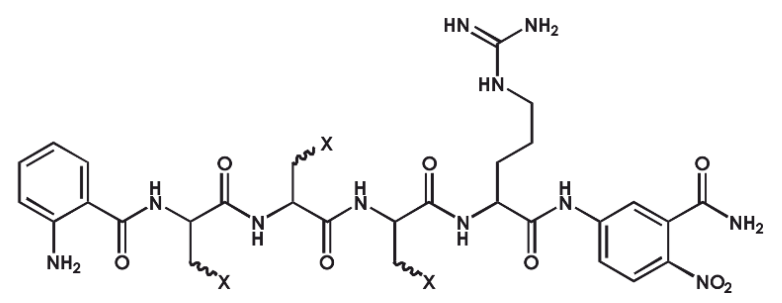

where X:

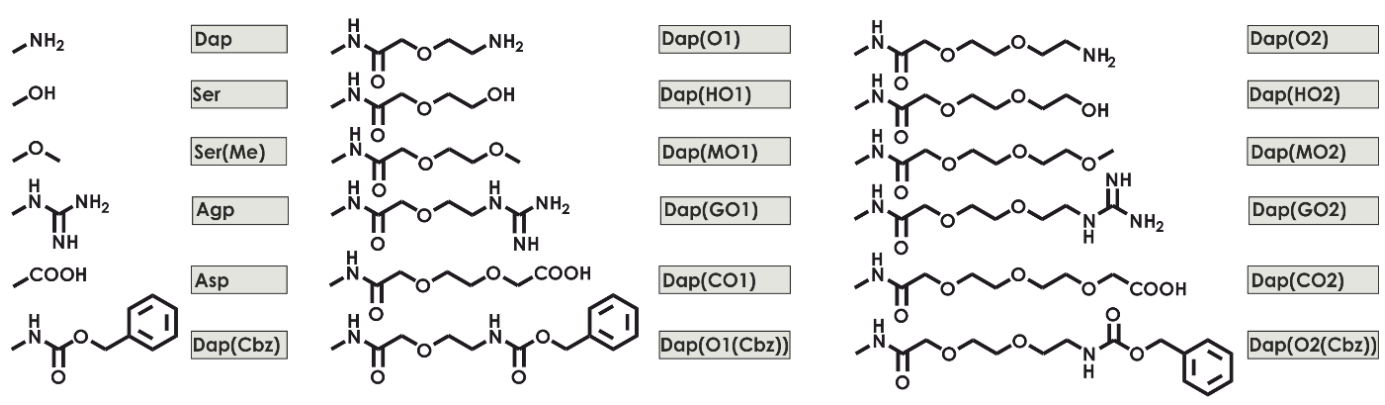

Figure 1. General formula for the library and its components. L-2,3- diaminopropionic acid (Dap), Ser, Ser(Me), L-2-amino-3- guanidino-propionic acid (Agp), Asp, Dap(Cbz), 5-(t-butyloxycarbonyl-amino) -3-oxapentanoic acid (abbreviated as O1), 2-(2-tert-butoxyethoxy) acetic acid (HO1), 5-methoxy-3-oxapentanoic acid (MO1), 5-[N-t-butyloxycarbonyl-N'-(2,2,4,6, 7-pentamethyldihydro benzofuran-5-sulfonyl)] amidino-3-oxapentanoic acid (GO1), 3,6dioxaoctanedioic acid 1-tert-butyl ester (CO1), 5-(benzyloxycarbonyl-amino)-3-oxa-pentanoic acid $(\mathrm{O} 1(\mathrm{Cbz}))$, 8-(t-butyloxycarbonyl-amino)-3, 6-dioxaoctanoic acid (O2), 2-(2-(2-tertbutoxyethoxy) ethoxy) acetic acid (HO2), 8-methoxy-3,6-dioxaoctanoic acid (MO2), 8-[N-tbutyloxycarbonyl - $\mathrm{N}^{\prime}$-(2,2,4,6, 7-pentamethyldihydrobenzofuran-5-sulfonyl)] amidino-3, 6-dioxaoctanoic acid (GO2), 3,6,9-trioxaundecandioic acid 1-tert-butyl ester (CO2), and 8(benzyloxycarbonyl-amino)-3,6-dioxaoctanoic acid (O2(Cbz)).

\section{Results and Discussion}

Deconvolution of the synthesized library with a fixed Arg in position P1 and diversified by DAPEG residues at positions P2-P4 was performed in a solution using a mix and split approach. By analyzing the starting position (e.g., P4), we found an above-average cleavage rate for the libraries with hydrophobic groups, such as carbobenzoxy or methyl, suggesting that interaction efficacy increased with side chain length. Hydrolyzation by the $20 \mathrm{~S}$ proteasome was significantly slower for charged or polar residues. Since the proteasome structure has three pairs of catalytically active subunits with distinct specificities (chymotrypsin, trypsin, and caspase), we repeated these experiments in the presence of a trypsin subunit inhibitor (PR671A) [20]. In effect, a 96\% reduction in activity was recorded. This observation allowed us to proceed with screening at position P3 (Figure 2A).

The incubation of 18 libraries with the general sequence ABZ-Dap $(\mathrm{O} 2(\mathrm{Cbz}))-\mathrm{X} 3-\mathrm{X} 2-\mathrm{Arg}-\mathrm{ANB}-\mathrm{NH}_{2}$ generated the highest fluorescence increases for positively charged DAPEG residues (with amino or guanidyl moieties), whereas hydrophobic or uncharged polar residues were poorly accepted at the analyzed position of P3. The highest fluorescence rate was observed for DAPEG with a guanidyl group located on its side chain, which is formed by a single ethylene unit. The velocity of Dap(GO1) was three times greater compared to that of the best $\mathrm{P} 4$ sub-library. The sub-library with the residue AGP (2-amino-3-guanidino-propionic acid) (shorter side chain) or GO2 was hydrolyzed significantly slower by the $20 \mathrm{~S}$ proteasome. The same side chain length dependence was observed for DAPEG residues with amino groups on the side chain, but with a half of the rate. Repetition of the assay in the presence of the above-mentioned selective inhibitor [20] with a C-terminal vinyl sulfone warhead for the $\beta 2$ subunit resulted in the total reduction of the proteolysis for this library (Figure 2B). 

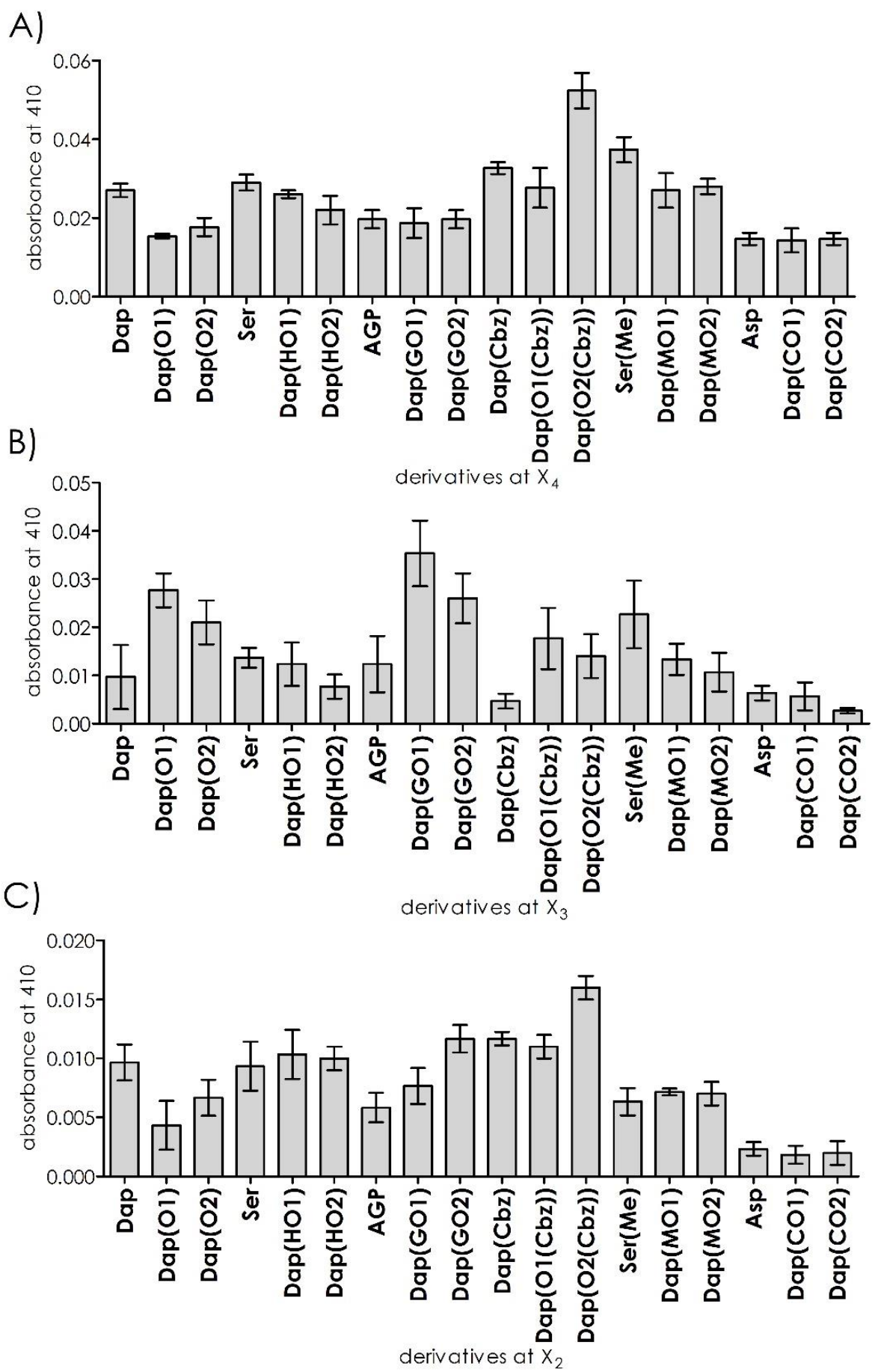

Figure 2. Deconvolution of the library (at an average concentration of $3.4 \times 10^{-6} \mathrm{M}$ ) with the general formula ABZ-X4-X3-X2-Arg-ANB-NH ${ }_{2}$ against the 20 S proteasome $\left(1.46 \times 10^{-9} \mathrm{M}\right)$. (A) Cleavage rates of individual sublibraries recorded for position $\mathrm{X} 4$; (B) Cleavage rates of individual sublibraries recorded for position $\mathrm{X} 3$; (C) Cleavage rates of individual compounds modified in position $\mathrm{X} 2$.

Next, a set of individual peptidomimetics with a defined position at P2, containing DAPEG residues or simple amino acid derivatives, were incubated with the $20 \mathrm{~S}$ proteasome. The highest fluorescence increases were recorded for the sets of residues with aromatic groups (carbobenzoxy), followed by hydroxyl DAPEGs derivatives. In this series, the optimal side chain length increased from Dap $(\mathrm{Cbz})$ and Dap $(\mathrm{O} 1(\mathrm{Cbz}))$ to attain a maximum for Dap $(\mathrm{O} 2(\mathrm{Cbz}))$. The same trend was observed for the hydroxy DAPEG derivatives. The basic charged side chain residues displayed 
moderate rates of fluorescence increases since the acidic residues significantly reduced proteolytic efficacy compared to the other tested systems. As expected, the cleavage rate increase for ABZ-Dap (O2(Cbz))-Dap(GO1)-Dap (O2(Cbz))-Arg-ANB- $\mathrm{NH}_{2}$ was significantly higher compared to the rates of the other tested systems. Moreover, when the assays were repeated in the presence of the selective $\beta 2$ subunit inhibitor, a potent reduction in proteolysis for all systems was observed (Figure 2C).

Finally, the compound ABZ-Dap(O2(Cbz))-Dap(GO1)-Dap(O2(Cbz))-Arg-ANB-NH 2 (1) was analyzed. Based on its reverse phase-high-performance liquid chromatography (RP-HPLC) profile (Figure 3A and mass spectrometry analysis (Figure 4)), the spectra clearly confirmed the compound purity and its expected mass. Incubation of the final substrate with the $20 \mathrm{~S}$ proteasome in assay buffer resulted in two products with retention times corresponding to ABZ-Dap $(\mathrm{O} 2(\mathrm{Cbz}))-\mathrm{Dap}(\mathrm{GO} 1)-\mathrm{Dap}(\mathrm{O} 2(\mathrm{Cbz}))-\mathrm{Arg}-\mathrm{OH}(2)\left(\mathrm{t}_{\mathrm{R}}=18.24\right)$ and $\mathrm{ABZ}-\mathrm{NH}_{2}\left(\mathrm{t}_{\mathrm{R}}=7.89\right)$ (Figure 3B).

A)

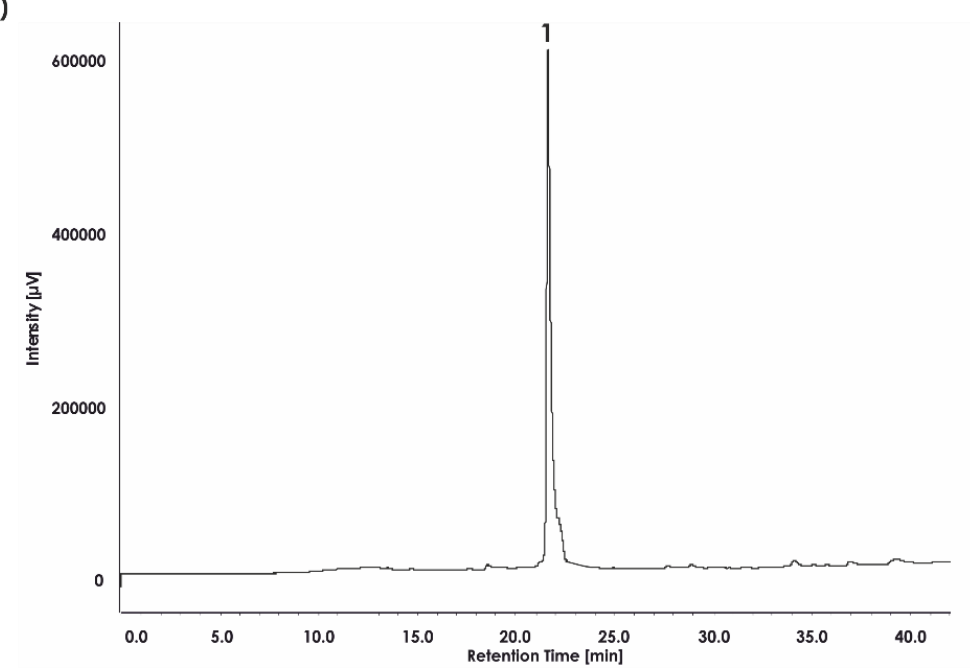

B)

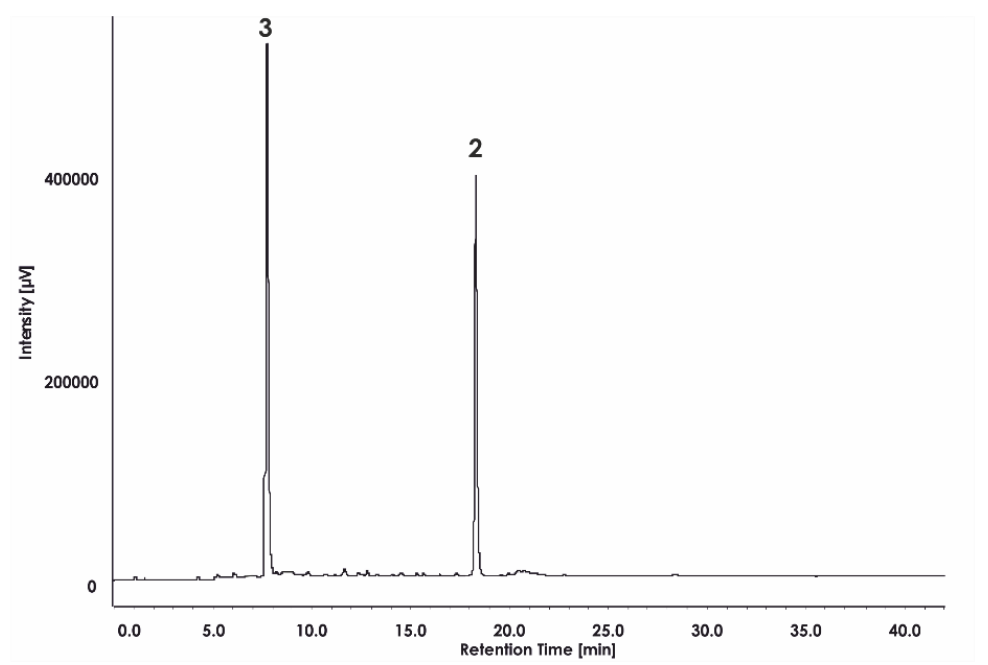

Figure 3. Reverse phase-high-performance liquid chromatography (RP-HPLC) analysis of (A) compound $1\left(t_{R}=22.41\right)$ and $(B)$ compound 1 incubated with the $20 \mathrm{~S}$ proteasome for one hour. The fragment ABZ-Dap(O2(Cbz))-Dap(GO1)-Dap $(\mathrm{O} 2(\mathrm{Cbz}))-\mathrm{Arg}-\mathrm{OH}(2)$ has a retention time of $t_{\mathrm{R}}=18.2$ and $\mathrm{ANB}-\mathrm{NH}_{2}(3), \mathrm{t}_{\mathrm{R}}=7.89$. 


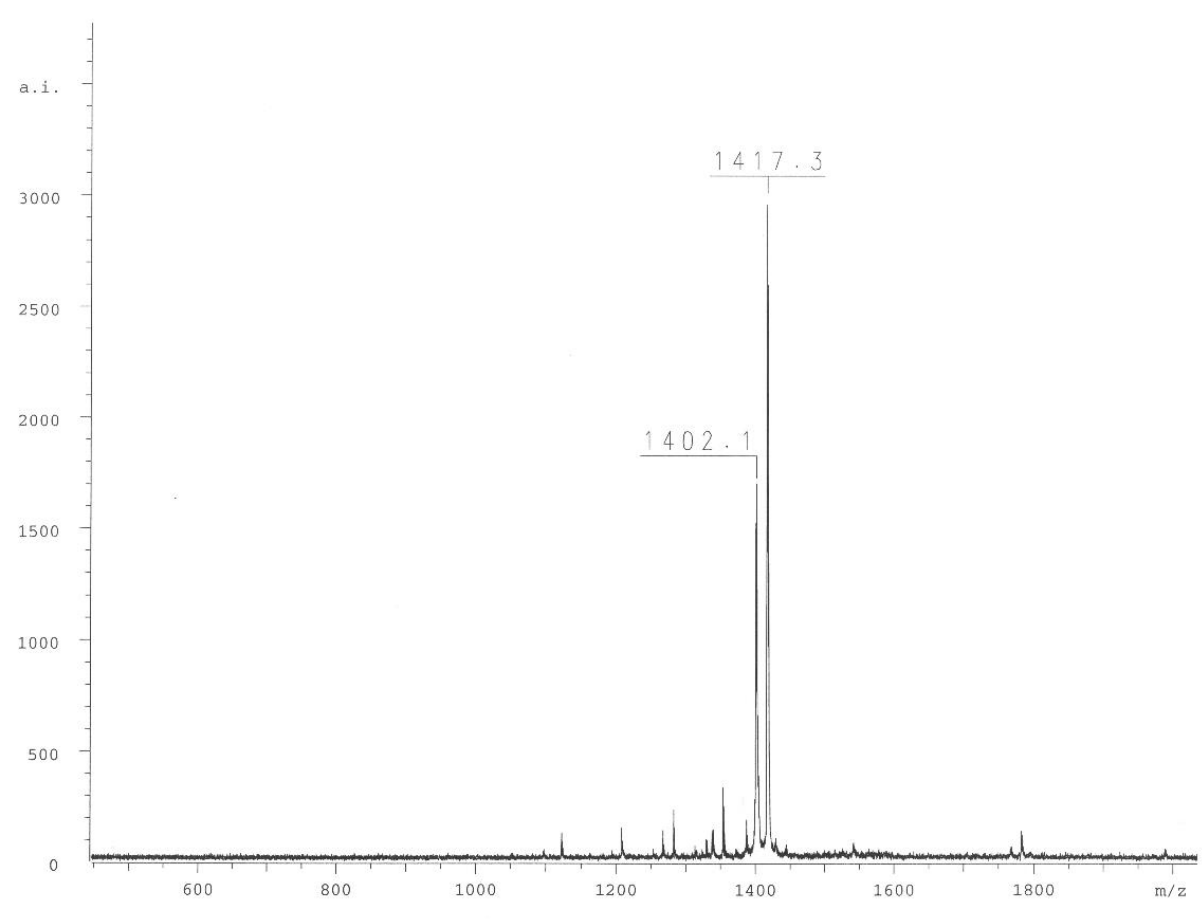

Figure 4. Mass spectrometry analysis of substrate $\mathbf{1}$.

Cleavage was not observed in the presence of the highly selective inhibitor of the $\beta 2$ sub-site (PR671A, [20]), a peptidomimetic with a C-terminal vinyl sulfone warhead. As shown in Figure 5, inhibition of the trypsin-like sub-site (using the general proteasome inhibitor, epoxomicin, or the PR671A inhibitor described above) resulted in the proteolytic suppression of substrate 1 . Inhibition of the remaining proteolytic sites, $\beta 5$ and $\beta 1$, did not influence this process. However, for carfilzomib, a slight activation of the cleavage rate was observed. This result indicates that the substrate was hydrolyzed exclusively by the $\beta 2$ sub-site.

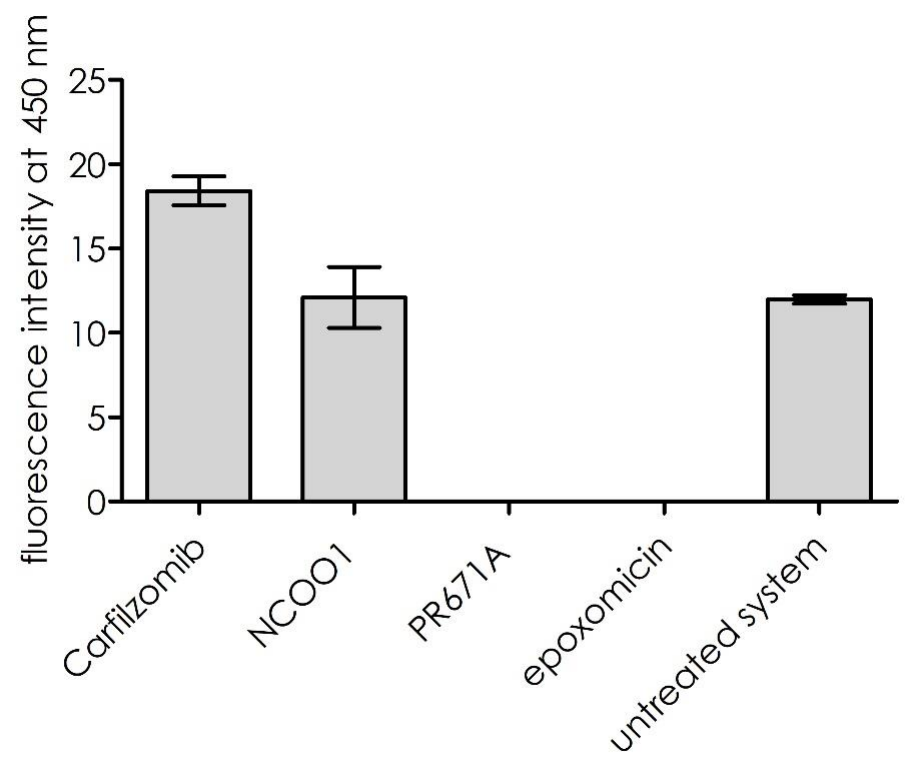

Figure 5. 20S proteasome activity in the presence of selective proteasome inhibitors. Compounds used in the study: carfilzomib, selective inhibitor of the $\beta 5$ subunit; NCOO1, selective inhibitor of the $\beta 1$ subunit, PR671A, selective inhibitor of the $\beta 2$ subunit; epoxomicin, general inhibitor of proteasome activity. 
Fluorescent substrate cleavage followed sigmoidal kinetics, which is characteristic for allosteric enzymes, with $K_{\mathrm{m}}=3.22 \pm 0.02 \mu \mathrm{M}, k_{\text {cat }}=245 \pm 21 \mathrm{~s}^{-1}$, and $k_{\text {cat }} / K_{\mathrm{m}}=7.61 \times 10^{7} \mathrm{M}^{-1} \mathrm{~s}^{-1}$ (Figure 6A). For the same experiments performed in the presence of the artificial proteasome activator, sodium dodecyl sulfate (SDS), the $K_{\mathrm{m}}$ values were twice as large $\left(K_{\mathrm{m}}=6.84 \pm 0.12 \mu \mathrm{M}\right)$, but the turnover value remained at a comparable level $\left(k_{\text {cat }}=221 \pm 18 \mathrm{~s}^{-1}\right.$ and $k_{\text {cat }} / K_{\mathrm{m}}=3.23 \times$ $\left.10^{7} \mathrm{M}^{-1} \mathrm{~s}^{-1}\right)$. The obtained kinetic values for substrate $\mathbf{1}$ were much greater than those reported for the other substrates of the proteasome reported by other groups (Table 1). Moreover, the $\beta 2$ subunit activity of the $20 \mathrm{~S}$ proteasome was not significantly altered in the presence of the $20 \mathrm{~S}$ proteasome activator, SDS (Figure 6B).

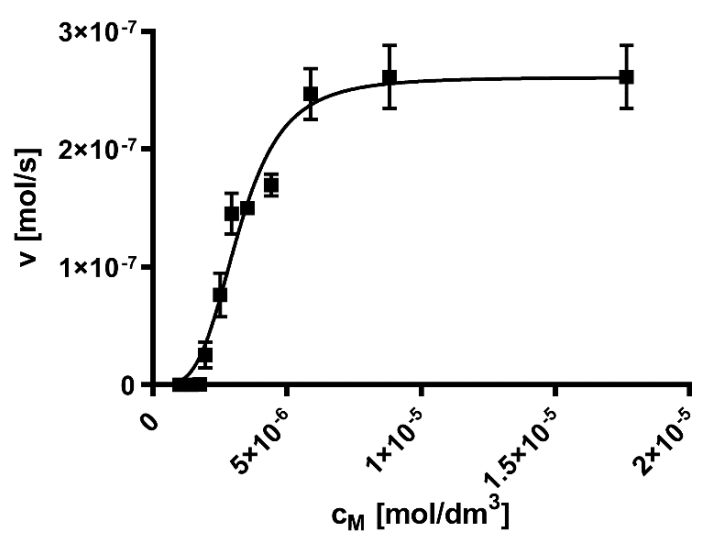

(A)

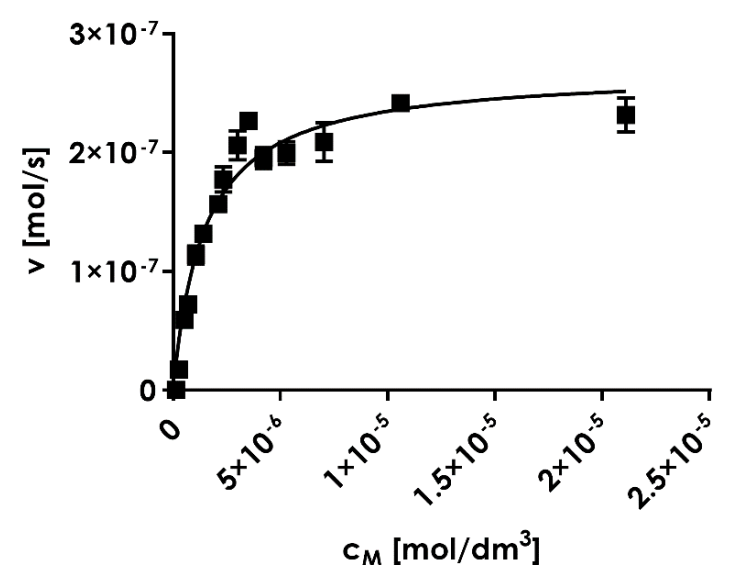

(B)

Figure 6. Kinetic curves for the 20S proteasome in two systems: (A) substrate alone and (B) in the presence of the artificial activator, $0.01 \%$ sodium dodecyl sulfate (SDS).

Table 1. Overview of the fluorogenic substrates of the trypsin-like subunit of the $20 \mathrm{~S}$ proteasome.

\begin{tabular}{|c|c|c|c|c|c|}
\hline No. & Sequence & $\begin{array}{c}K_{m} \\
(\mu \mathrm{M})\end{array}$ & $\begin{array}{l}k_{\text {cat }} \\
\left(\mathrm{s}^{-1}\right)\end{array}$ & $\begin{array}{c}k_{\text {cat }} / K_{m} \\
\left(\mathbf{M}^{-1} \mathbf{s}^{-1}\right)\end{array}$ & Ref. \\
\hline 1 & ABZ-Val-Val-Ser-GNF-Ala-Met-Gly-Tyr $\left(3-\mathrm{NO}_{2}\right)-\mathrm{NH}_{2}$ & $4.24 \pm 0.87$ & $8.41 \pm 0.57$ & $1,983,100 \pm 2754$ & [21] \\
\hline 2 & Boc-Leu-Arg-Arg-AMC & & & $<500$ & [22] \\
\hline 3 & Ac-DArg-hSer-Thr-Arg-ACC & $9.43 \pm 0.82$ & $2.84 \pm 0.22$ & $301,005 \pm 28,471$ & [18] \\
\hline 4 & Ac- $\beta$ Ala-Met $(\mathrm{O})_{2}-$ Thr-Arg-ACC & $50.9 \pm 2.99$ & $2.23 \pm 0.07$ & $43,790 \pm 3233$ & [18] \\
\hline
\end{tabular}

To elucidate the data from the deconvolution experiments, we performed in silico docking using the PLANTS program [23]. For calculations, we used the crystal structure of the human $20 \mathrm{~S}$ proteasome (protein database ( $\mathrm{pdb}$ ) code 4R67) in complex with the carfilzomib potent inhibitor of the proteasome [24]. $\beta 2$ and $\beta 3$ (using the yeast nomenclature) were extracted and used for the docking simulations. Two sequential docking calculations were performed under the following conditions: The number of ants used by the software to search for the protein binding pocket was set to 40 , and the number of resulting conformations was set to 30 .

In the first "blind docking" experiment, only the space around the S1 and S3 binding pockets was declared. In the second docking experiment, the positional restraint was set on the Arg residue located in the S1 binding pocket. Using this procedure, we sought to verify that the Arg residue was in the vicinity of the S1 binding pocket. Our analysis revealed that the only residue located in the binding pocket was Arg. The second docking sequence was performed with the distance restraint set to the Arg residue. For this subunit, the S1 binding pocket was considerably larger than the $\beta 1$ 
and $\beta 5$ subunits and was comprised of the following residues: His35, Thr52, and Asp53. Analysis of the binding interface of carfilzomib with $\beta 2$ and $\beta 3$ showed that the Leu side chain (P1) was in the $\mathrm{S} 1$ binding pocket. In our case, this was the residue in position X3-Dap(GO1). According to the deconvolution experiments, four residues were optimal for this position: Dap(GO1), Dap(GO2), $\operatorname{Dap}(\mathrm{O} 1)$, and Dap $(\mathrm{O} 2)$. Since the S1 binding pocket was acidic, basic residues were ideal for creating an optimal interaction. The residues Dap(CO1), Dap (CO2), and Asp did not work at all, whereas the Ser and Dap residues were too small to accommodate the binding pocket. The other possibility was to create $\pi-\pi$ interactions with the ligand by using His at position 35 . However, the S1 binding pocket was too small to accommodate the three stacking rings Dap $(\mathrm{Cbz})$, Dap $(\mathrm{O} 1(\mathrm{Cbz}))$, and Dap $(\mathrm{O} 2(\mathrm{Cbz}))$.

The residue at position X2 was located in the S3 binding pocket. Analysis of the binding interface of carfilzomib with $\beta 2$ and $\beta 3$ showed that the Leu side chain (P3) was located in the S3 binding pocket. Asp125 was located at the entrance of the S3 binding pocket. Therefore, all acidic residues may have had a negative influence on the binding affinities. This was confirmed by the deconvolution experiments, since residues Asp, Dap(CO1), and Dap(CO2) did not bind at all. The S3 binding pocket passed through the interface between the $\beta 2$ and $\beta 3$ subunits. Only the $\operatorname{Dap}(\mathrm{O} 2(\mathrm{Cbz}))$ residue was long enough to accommodate the entire space of the binding pocket.

Most of the residues at position X4 worked well since they were in the grove of the proteasome. The greater the number of interactions, the greater the binding affinity, which was true for $\operatorname{Dap}(\mathrm{O} 2(\mathrm{Cbz}))$.

According to Reference [23], for trypsin-like sites, the S1 and S3 binding pockets are larger than those for caspase- and chymotrypsin-like sites. This was clearly visible from our $20 S$ proteasome structure analysis. Presumably, the structure of the mentioned binding pockets explains the selectivity of our ligand. According to the molecular modeling results, two relatively large residues were located in these pockets (Figure 7). This was not possible for caspase- and chymotrypsin-like sites. Similarly, these sites did not have acidic environments like those of trypsin-like sites. Only this site had perfect conditions for the base-like residues Dap(GO1) or Dap(GO2).

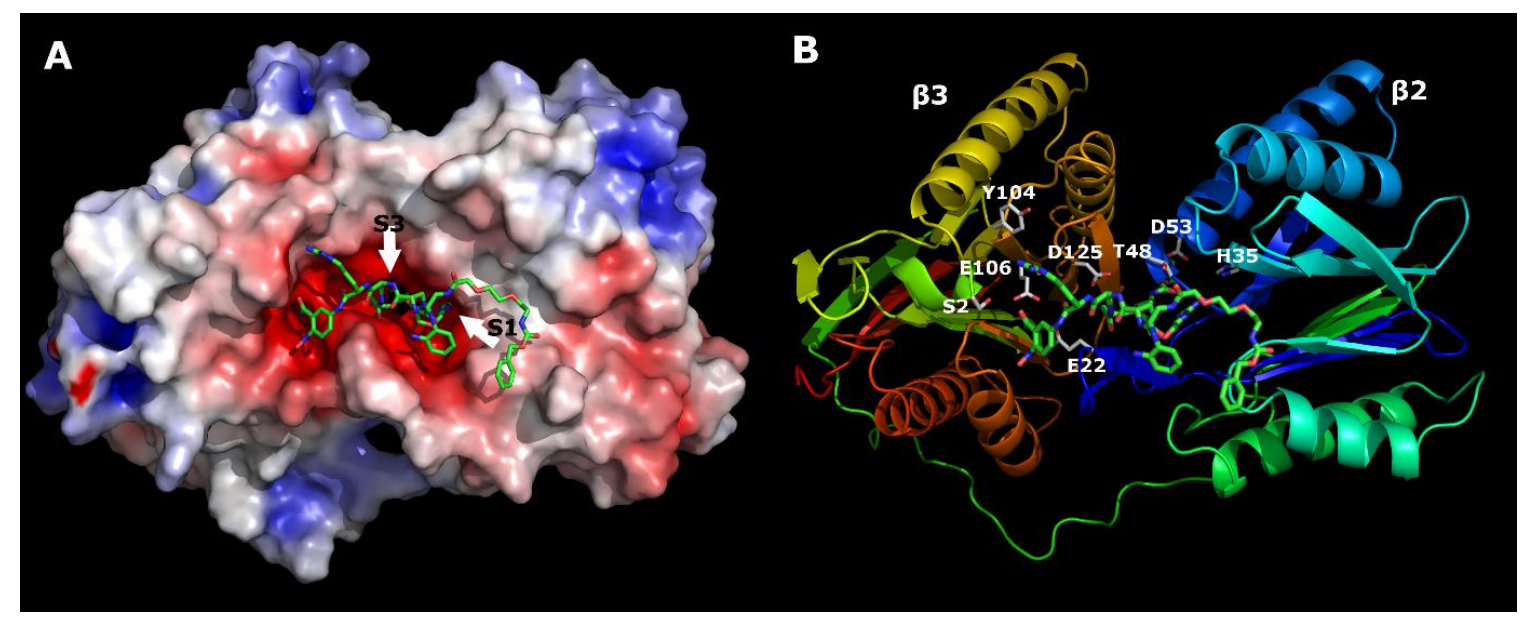

Figure 7. Theoretical model of the ligand ABZ-Dap(O2(Cbz))-Dap(GO1)-Dap(O2(Cbz))-Arg-ANB-NH 2 interacting with $\beta 2$ and $\beta 3$ subunits of the $20 S$ proteasome. (A) Electrostatic surface (red: negative charge; blue: positive charge), (B) the most important residues at the proteasome-ligand interface. Arrows indicate the location of the S1 and S3 binding pockets.

The titration of decreasing proteasome $20 \mathrm{~S}$ concentrations with substrate $\mathbf{1}$ resulted in a concentration-dependent increase in fluorescence to $8.9310^{-11} \mathrm{M}$ (Figure 8). 


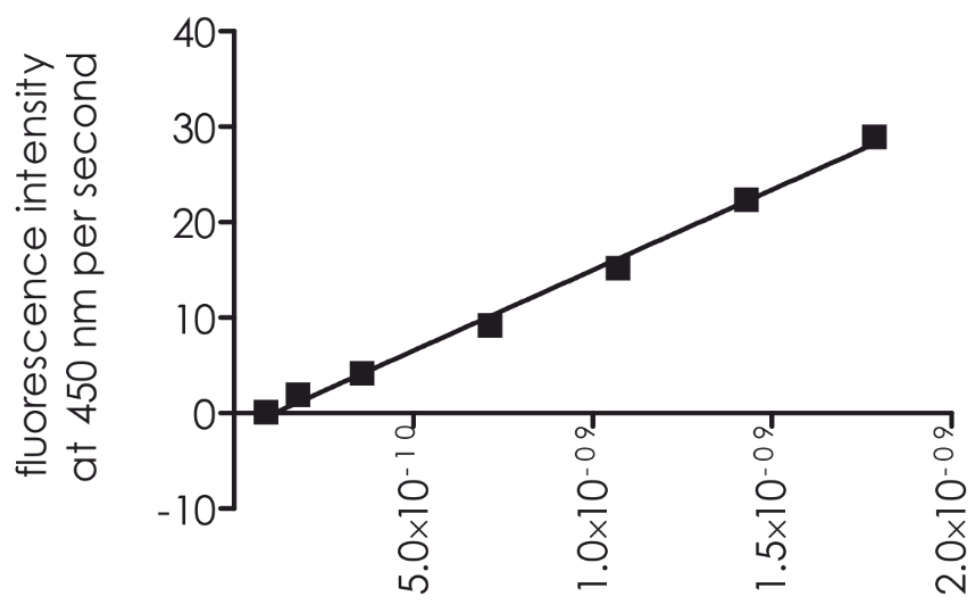

enzyme concentration [M]

Figure 8. The $20 \mathrm{~S}$ proteasome assay detection limits. The following $20 \mathrm{~S}$ proteasome concentrations were analyzed: (1) $2 \times 10^{-9} \mathrm{M}$, (2) $1.5 \times 10^{-9} \mathrm{M}$, (3) $1 \times 10^{-9} \mathrm{M}$, (4) $0.75 \times 10^{-9} \mathrm{M}$, (5) $0.4 \times 10^{-9} \mathrm{M}$, (6) $0.1 \times 10^{-9} \mathrm{M}$, and (7) $0.05 \times 10^{-9} \mathrm{M}$.

Next, we tested how substrate $\mathbf{1}$ was processed by the other proteasomal entities, such as proteasome $26 \mathrm{~S}$ and immunoproteasome 20S. Initial screening showed that substrate $\mathbf{1}$ was selectively proteolyzed by the $20 \mathrm{~S}$ proteasome (Figure 9 ).

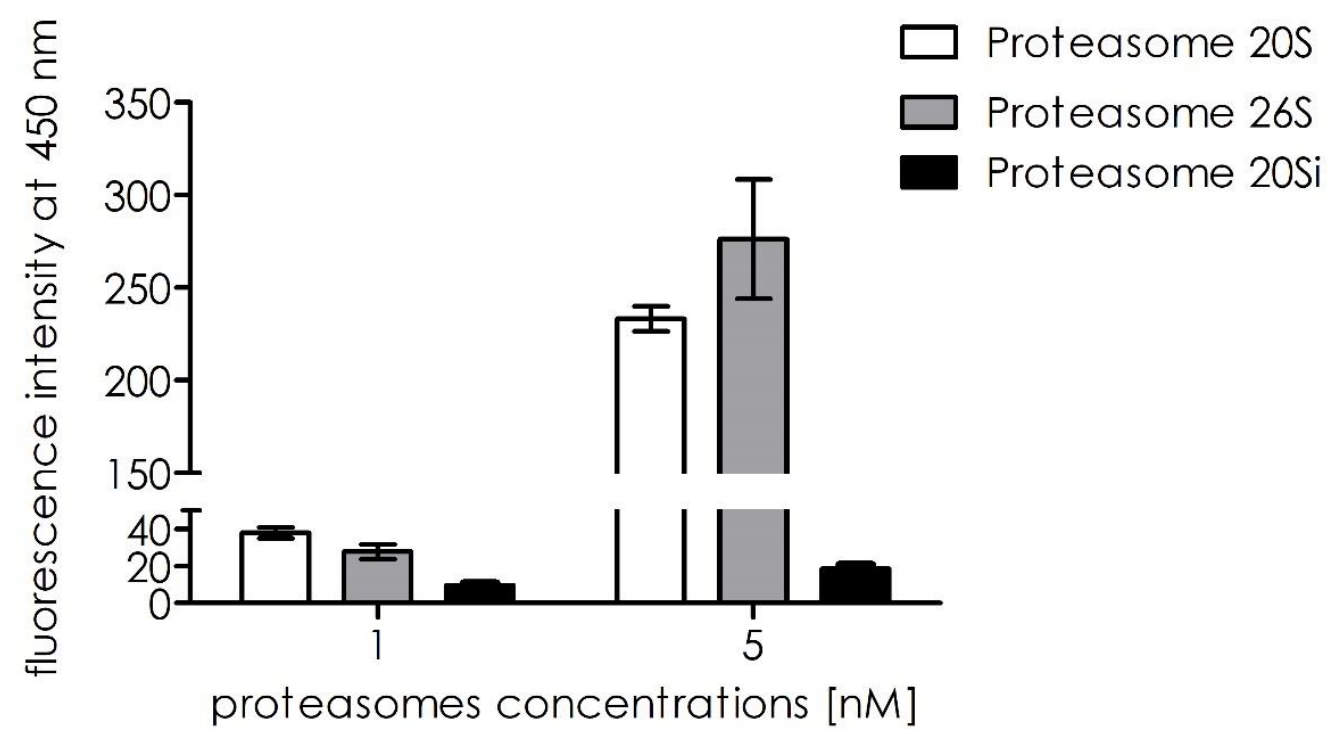

Figure 9. Substrate cleavage rates for the 20S, 26S, and 20S immunoproteasome entities at equimolar concentrations.

Next, we evaluated the ability of substrate 1 to detect proteasome activity in biological samples. As previously reported, elevated 20S proteasome activity in human urine is often linked to a diagnosis of bladder cancer [21]. To verify whether substrate 1 could be used in such an assay, we recorded its cleavage intensity in healthy $(n=5)$ urine samples and bladder cancer urine $(n=8)$ samples. As observed (Figure 10A), the healthy urine samples displayed insignificant background levels of fluorescence (red line). However, for the urine sample from bladder cancer patients, the proteasome activity resulted in a fluorescence increase that was observed in all samples (green line). The incubation of samples with a specific $20 \mathrm{~S}$ proteasome inhibitor resulted in significant reductions in cleavage rates (blue line). As shown in Figure 10B (a summary of the experiments), there is a significant difference in 
the activity recorded for the healthy $(n=5$, mean $0.1 \pm 0.04)$ and bladder cancer urine samples $(n=8$, mean $48.4 \pm 28.1$ ). The results for the analysis of the same samples with the substrate design for the chymotrypsin subunit ( $\beta 5$ ) of the $20 S$ proteasome were acquired under the same conditions used for substrate $\mathbf{1}$ and for the system supplemented by the artificial activator (SDS) of the 20S proteasome, as presented in Figure 11. For systems lacking SDS, the fluorescence increase is visible for only 2 out of the 8 bladder cancer samples. An increase in fluorescence was observed for seven systems $(1-5,7$, and 8 ) with SDS among the assay systems. For one sample $\left(\mathrm{N}^{\circ} 6\right)$, the rate was insignificant. For all systems, the samples that originated from healthy persons displayed no visible fluorescence increase.

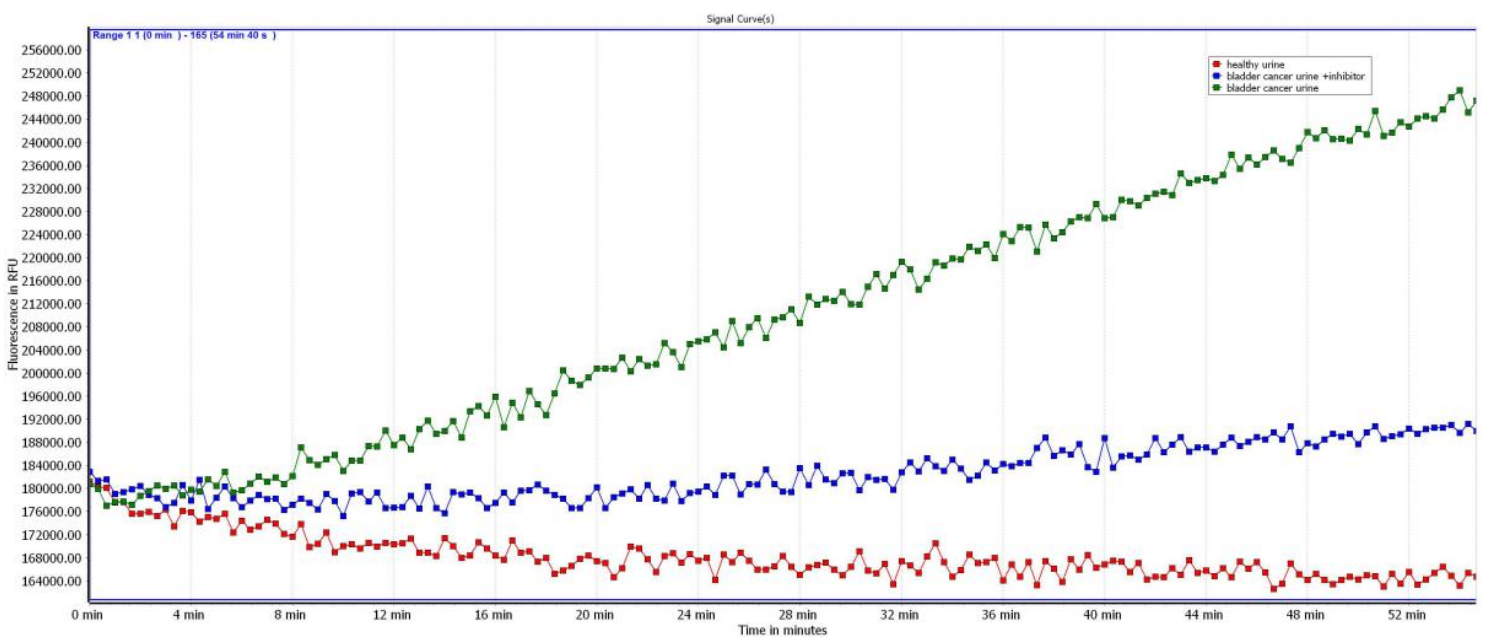

(A)

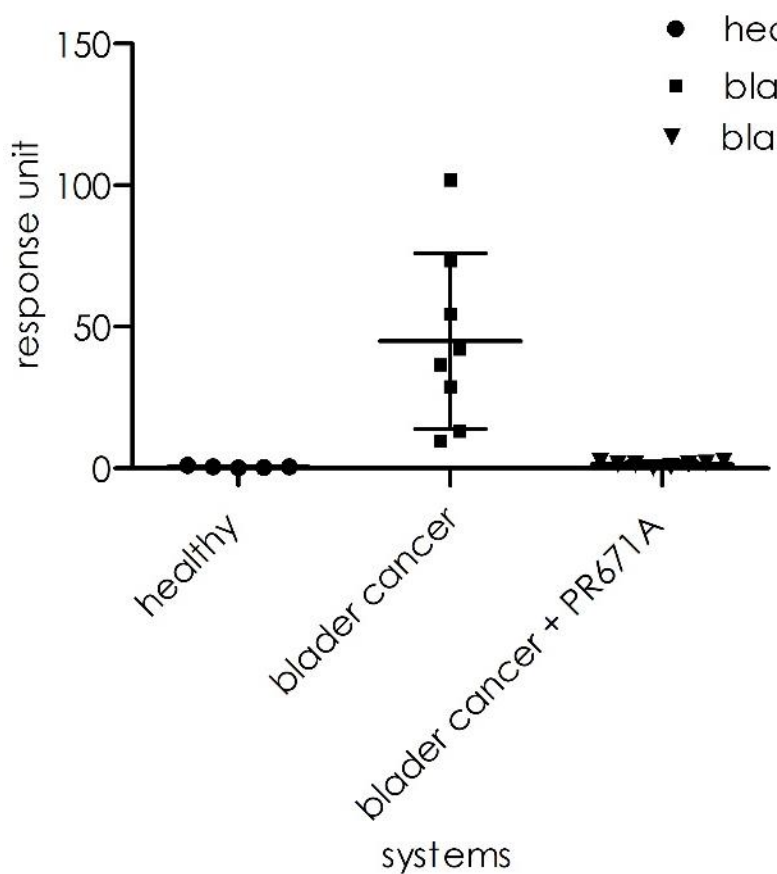

(B)

Figure 10. (A) Fluorescence curves for the three the systems: healthy urine (red line), bladder cancer urine (green line), and inhibitor-treated bladder cancer urine (blue), (B) aggregate analysis of the healthy and bladder cancer urine and inhibitor-treated urine. 


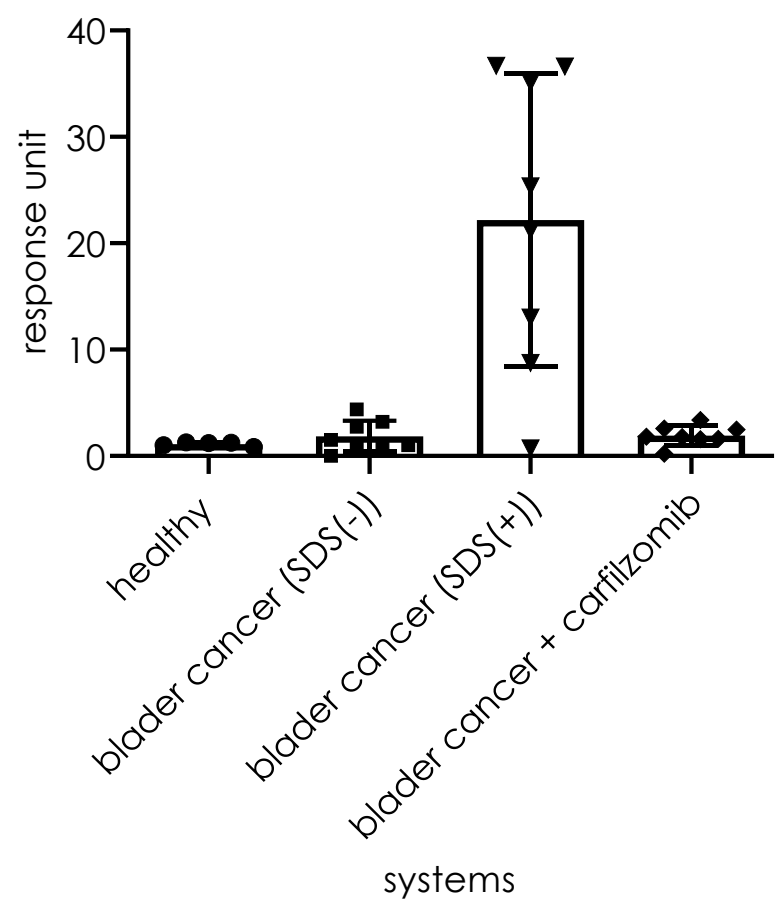

Figure 11. Aggregate analysis of the healthy and bladder cancer urine and inhibitor-treated urine.

\section{Materials and Methods}

Synthesis of the ANB-based library, where ANB is 5-amino-2-nitrobenzoic acid, was initiated by the deprotection of the amino groups of Tenta Gel SRAM resin (Rapp Polymeres, Tubingen, Germany) with $20 \%$ piperidine in dimethylformamide (DMF). The attachment of 5-amino-2-nitrobenzoic acid (ANB) used the following reagents: $N, N, N^{\prime}, N^{\prime}$-tetramethyl-O-(benzotriazol-1-yl)uronium tetrafluoroborate (TBTU)/4-dimethylaminopyridine (DMAP). After this procedure, the resin was mixed with 5\% $\mathrm{N}$-methylmorpholine in DMF, and the solution was removed. This step was repeated twice. Next, three equivalents of ANB were dissolved in DMF, and three equivalents of TBTU were added, followed by two equivalents of DMAP. This solution was added to the resin, and after $30 \mathrm{~s}$, six equivalents of $\mathrm{N}, \mathrm{N}$-diisopropylethylamine (DIPEA) were added. The mixture was then stirred for $3 \mathrm{~h}$.

The solution was filtered using a Schott funnel (MO5), and the resin was washed in DMF. This procedure was repeated three times. Next, the first amino acid residue was coupled using a previously described method [21,25]. A nine-fold amino acid excess was applied to the active resin sites as follows: the amino acid residue was dispersed in pyridine (for each $1 \mathrm{~g}$ of peptidyl resin, $10 \mathrm{~mL}$ pieridine was used). The solution was stirred until its temperature reached $-15^{\circ} \mathrm{C}$, and then nine equivalents ofphosphorus oxychloride $\mathrm{POCl}_{3}$ were added. The mixture was stirred for $20 \mathrm{~min}$ at $-15{ }^{\circ} \mathrm{C}$, for $20 \mathrm{~min}$ at room temperature, and then for $6 \mathrm{~h}$ in an oil bath at $40{ }^{\circ} \mathrm{C}$. After deprotection of the Fmoc-protecting group with $20 \%$ piperidine in DMF, the peptide chain was elongated as follows: The solid support was split into 18 identical portions, with six of them containing one of the following standard protected amino acid derivatives: Fmoc-Asp(tBu), Fmoc-Ser(OtBu), Fmoc-Ser(OMe), Fmoc-Dap(Cbz), Fmoc-Agp(Boc) $)_{2}$, and Fmoc-Dap(Boc), which were attached using a standard Fmoc synthesis procedure. Fmoc-Dap(Mtt) was introduced to the remaining 12 portions, and 4-methyltrityl (Mtt) was removed using a previously described procedure [19] (1\% TFA in DCM with the addition of $2 \%$ triisopropylsilane). This mixture was added to all 12 portions and stirred for $15 \mathrm{~min}$. Complete $\mathrm{Mtt}$ removal was verified by adding a minimal portion of peptidyl resin with pure TFA. A yellow color was used to monitor the absence of free Mtt groups. This procedure was repeated until no absorbance increases at $410 \mathrm{~nm}$ were recorded. This step was followed by adding 1\% DIPEA in DMF solution to each system for $3 \times 1 \mathrm{~min}$, resulting in 12 portions of a Fmoc-Dap-Arg-ANB-polymer. To each resin aliquot, mono-protected heterobifunctional polyethylene glycol moieties (PEG: O1, HO1, MO1, 
$\mathrm{GO} 1, \mathrm{CO} 1, \mathrm{O} 1(\mathrm{Cbz}), \mathrm{O} 2, \mathrm{HO} 2, \mathrm{MO} 2, \mathrm{GO} 2, \mathrm{CO} 2, \mathrm{O} 2(\mathrm{Cbz})$ ) were introduced while applying equimolar quantities of PEG/DIPCI/HOBt in a DMF/NMP (1:1 (v/v)) solution. Subsequently, the following fully protected PEG derivatives were applied: 5-(t-butyloxycarbonyl-amino)-3-oxapentanoic acid (O1), 8-(t-butyloxycarbonyl-amino)-3,6-dioxaoctanoic acid (O2),5-[N-t-butyloxycarbonyl-N'-(2,2,4,6, 7-pentamethyldihydrobenzofuran-5-sulfonyl)]amidino-3-oxapentanoic acid (GO1), 8-[N-tbutyloxycarbonyl-N'-(2,2,4,6,7-pentamethyldihydrobenzofuran-5-sulfonyl)]amidino-3,6-dioxaoctanoic acid (GO2), 5-(benzyloxycarbonyl-amino)-3-oxa-pentanoic acid (O1(Cbz)), 8-(benzyloxycarbonylamino)-3,6-dioxaoctanoic acid (O2(Cbz)), 2-(2-tert-butoxyethoxy) acetic acid (HO1), 2-(2-(2-tert-butoxyethoxy)ethoxy) acetic acid (HO2), 3,6-dioxaoctanedioic acid 1-tert-butyl ester (CO1), 3,6,9-trioxaundecandioic acid 1-tert-butyl ester (CO2), 5-methoxy-3-oxapentanoic acid (MO1), and 8-methoxy-3,6-dioxaoctanoic acid (MO2). Coupling completeness was monitored using a Kaiser test. A lack of free amino groups facilitated the next step in library synthesis, where all resin portions were mixed and divided into 18 parts. A total of $20 \%$ of the peptidyl resin from each portion was removed and stored for further deconvolution processes. The above-mentioned method was repeated once again. Next, the tert-butyloxycarbonyl derivative of 2-amino benzoic acid (Boc-ABZ-OH) was used and coupled to the N-terminal amino group via the procedure used earlier.

After completing the synthesis, sub-libraries or particular compounds were detached from the solid support using a TFA/phenol/triisopropylsilane/ $\mathrm{H}_{2} \mathrm{O}$ mixture (88:5:2:5 (v/v)) [25]. Compound purity and synthesis were verified using an RP-HPLC ChromNAV (Jasco, Japan) with a Kromasil 100 C8 column (Knauer, Germany) coupled to a UV-Vis and fluorescence detector. A linear gradient was used from 10\% to $90 \%$ solution B over 45 min (A: 0.1\% TFA; B: 80\% acetonitrile in A). The peptides were assayed at $208 \mathrm{~nm}$. The molecular weights of the obtained compounds were obtained by mass spectrometry and recorded on a Biflex III MALDI TOF mass spectrometer (Bruker Daltonics, Hamburg, Germany) using a matrix ( $\alpha$-cyano-4-hydroxycinnamic acid).

\subsection{Preparation of Peptide Libraries}

The peptide libraries were synthesized using a portioning-mixing method [26]. Initially, $17.7 \mathrm{~g}$ of solid support (Tenta Gel SRAM Tubingen, Germany) was used (i.e., ABZ-X4-X3-X2-Arg-ANB- $\mathrm{NH}_{2}$ ). A double excess of each library building block (amino acid or monoprotected PEG derivative) was used for the synthesis. Other techniques applied in the library preparation are described above. After attachment of the ANB followed by Fmoc-Arg(Pbf) and Fmoc removal, the initial amount of the resin was split into 18 equal parts (related to the number of building blocks used for synthesis of the library). After successful attachment of the chemical derivatives, $15 \%$ of the resin portion with $\mathrm{ANB}-\mathrm{Arg}(\mathrm{Pbf})-\mathrm{P} 2$ was put aside until the deconvolution process. The Fmoc protection group was removed from the remaining $85 \%$ of the library, and the total amount of the resin was again split into 18 equal parts. This synthetic procedure, referred to as "mix and split", was repeated until position P4 was reached. In this final stage of library construction, the resin was not mixed, but all peptidomimetics were detached from the resin and subjected to enzymatic studies performed by applying the iterative method. In the first stage, the most active residue was selected via an enzymatic assay and, in subsequent synthetic steps, this residue was attached to the remaining $15 \%$ portion of the resin. This process was repeated (three times) until the final substrate sequence was selected [27].

\subsection{Enzymatic Studies}

For enzymatic studies, the human $20 \mathrm{~S}$ proteasome, 26S proteasome, and $20 \mathrm{~S}$ immunoproteasome were purchased from Boston Biochem (Cambridge, MA, USA). The 20S proteasome concentration for library deconvolution was in the nanomolar range, and this proteasome entity was used for the main study. Deconvolution of the peptide libraries was performed using the iterative solution method [28]. Dimethyl sulfoxide (DMSO) was used as a solvent for preparation of the stock solution $(5 \mathrm{mg} / \mathrm{mL})$ for each lyophilized sub-library. This stock solution was diluted ten times using an assay buffer (50 mM Tris/ $\mathrm{HCl}$ buffer ( $\mathrm{pH}$ 8.2)) for the $20 \mathrm{~S}$ and 20Si proteasome, and for 26S, the buffer was 
supplemented with $40 \mathrm{mM} \mathrm{KCl}, 2 \mathrm{mM}$ EDTA, $1 \mathrm{mM}$ DTT, $100 \mu \mathrm{M}$ ATP, and $50 \mu \mathrm{g} / \mathrm{mL}$ bovine serum albumin (BSA). The volume composition of each well of the 96-well plate was: $20 \mu \mathrm{L}$ library, $160 \mu \mathrm{L}$ assay buffer, and $20 \mu \mathrm{L} 20 \mathrm{~S}$ proteasome solution at a concentration of $1.07 \times 10^{-9} \mathrm{M}$. Absorbance or fluorescence measurements were performed on a FluoroStar OMEGA multimode microplate reader (BMG, Ortenberg, Germany). Absorbance increases were monitored at $410 \mathrm{~nm}$. The excitation and emission wavelengths were 320 and $450 \mathrm{~nm}$ respectively, for the ABZ/ANB. Enzymatic hydrolysis of the peptide was performed in the assay buffer at $37^{\circ} \mathrm{C}$ and continued over $60 \mathrm{~min}$.

\subsection{Determination of Kinetic Parameters}

The procedures to determine the kinetic constants $K_{\mathrm{m}}$ and $k_{\text {cat }}$ are described below. Increasing concentrations of substrate 1 ranged from $1 \times 10^{-6}$ to $2 \times 10^{-5} \mathrm{M}$. In parallel, a kinetic assay with the artificial activator SDS at $0.01 \%$ was also performed. The data were fitted to an allosteric plot using GraphPad prism v6.0 (GraphPad Software Inc., La Jolla, CA, USA). The specificity constants $\left(k_{\text {cat }} / K_{\mathrm{m}}\right)$ were calculated from the $k_{\text {cat }}$ and $K_{\mathrm{m}}$ values. Measurements were performed using a $20 \mathrm{~S}$ proteasome concentration of $1.07 \times 10^{-9} \mathrm{M}$. Three to five measurements were performed for each compound dilution (the systematic error, defined as the standard deviation, never surpassed $20 \%$ ). The initial hydrolysis rates were used as the amount of enzymatic activity for the tested compounds. All kinetic study details and kinetic parameters have been described elsewhere [21,25].

\subsection{Determination of Proteolytic Cleavage Patterns}

For each sample of the diluted substrate (concentration; $3.1 \times 10^{-6} \mathrm{M}$ ), an appropriate amount of proteasome $\left(1.07 \times 10^{-9} \mathrm{M}\right)$ was added, and the solution was incubated for 5, 30, and $60 \mathrm{~min}$. The proteolytic reaction was monitored by RP-HPLC.

\subsection{Titration}

A total of $160 \mu \mathrm{L}$ assay buffer was added to each well of the 96-well plate, containing a constant substrate concentration $\left(1.34 \times 10^{-5} \mathrm{M}\right)(20 \mu \mathrm{L})$, followed by $20 \mu \mathrm{L}$ of the $20 \mathrm{~S}$ proteasome, with concentrations ranging from 0.05 to $2 \mathrm{nM}$. In total, seven different concentrations were used. The excitation and emission wavelengths were 320 and $450 \mathrm{~nm}$, respectively. Enzymatic hydrolysis of the peptide was performed in the previously described buffer at $37{ }^{\circ} \mathrm{C}$ and continued over $30 \mathrm{~min}$. A linear fragment of the curve was chosen, and the slope was calculated for each system. All measurements were performed in triplicate.

\subsection{Inhibitory Studies}

A black, 96-well flat-bottomed microplate (Brand GMBH, Wertheim, Germany) was used for the inhibitory studies. Two inhibitors, carfilzomib (a selective inhibitor of the $\beta 5$ subunit of the $20 \mathrm{~S}$ proteasome) and epoxomicin, were purchased from Merck (Darmstadt, Germany) and used at final concentrations of $1.15 \times 10^{-6} \mathrm{M}$ and $5.0 \times 10^{-5} \mathrm{M}$, respectively. The $\beta 2$ inhibitor, PR671 A [20], and the $\beta 1$ inhibitor, NCOO1 [21], were used at a concentration of $5 \times 10^{-6} \mathrm{M}$. These reagents were kindly provided by Alexei Kisselev from Dartmouth University (Dartmouth, NH, USA). The concentration of $20 \mathrm{~S}$ proteasome was $1.07 \times 10^{-9} \mathrm{M}$. The buffered proteasome solution was mixed with $10 \mu \mathrm{L}$ inhibitor solution. This mixture was incubated for $30 \mathrm{~min}$ at $37^{\circ} \mathrm{C}$. After this period, the substrate solution was added at a concentration of $1.34 \times 10^{-5} \mathrm{M}$, and the fluorescence was measured over time at $320 \mathrm{~nm}$ excitation and $450 \mathrm{~nm}$ emission wavelengths. All measurements were performed in triplicate.

\subsection{Biological Studies}

All urine samples were purchased from St. Vincent de Paul Hospital in Gdynia, Poland (contract no. JN/777/R720/08.11.17). All methods and procedures were performed in accordance with this contract agreement. Participants were informed about the study and sample collection, and their 
written consent was collected. Urine samples did not reveal any personal information except for gender, age, and disease stage. Therefore, the samples were considered unnamed. The samples of human urine were taken during mid-urination and kept for $48 \mathrm{~h}$ at $-80^{\circ} \mathrm{C}$ until required. All samples used for assay development were taken from healthy volunteers $(n=5)$, and oncological samples were obtained from patients diagnosed with bladder cancer $(n=8)$.

The urine samples were thawed at room temperature, gently vortexed, and briefly centrifuged $(<20 \mathrm{~s})$ to collect the sample at the bottom of the tube. A total of $80 \mu \mathrm{L}$ urine was transferred to a 96-well microplate and mixed with assay buffer and substrate 1 . Proteasome activity was assayed as described earlier. Briefly, $80 \mu \mathrm{L}$ of urine from healthy volunteers, urine from patients diagnosed with bladder cancer, and bladder cancer urine supplemented by the inhibitor PR671A were mixed with $200 \mu \mathrm{L}$ of the assayed buffer and $20 \mu \mathrm{L}$ of the substrate at a concentration of $1.34 \times 10^{-5} \mathrm{M}$, and the fluorescence was quantified. An excitation wavelength equal to $320 \mathrm{~nm}$ and an emission wavelength of $450 \mathrm{~nm}$ were used.

In parallel, the urine samples were analyzed using the previously developed substrate ABZ-Val-Val-Ser-Tyr-Ala-Met-Gly-Tyr $\left(3-\mathrm{NO}_{2}\right)-\mathrm{NH}_{2}$ [21] in two systems: one with the artificial activator SDS at $0.01 \%$ and the second without any SDS. The fluorescence of the system was recorded over time. The same conditions for excitation and emission were used as above. All measurements were performed in triplicate.

The resulting data were analyzed using Graphpad Prism version 6.0 software (GraphPad Software Inc., La Jolla, CA, USA). All fluorescent measurements were performed in triplicate and represented by the mean \pm standard deviation (SD). A two-tailed Mann-Whitney test was applied for the statistical analysis $(p<0.0001)$.

\section{Conclusions}

We developed a new $20 \mathrm{~S}$ proteasome fluorescent peptidomimetic probe with superior kinetic parameters, yielding $7.61 \times 10^{7} \mathrm{M}^{-1} \mathrm{~s}^{-1}$. The synthesized substrate was cleaved at a minimal $20 \mathrm{~S}$ proteasome level at $10^{-11} \mathrm{M}$. Based on a putative model derived from molecular docking, the probe interacts with the $20 \mathrm{~S}$ proteasome using secondary binding sites located distally from the catalytic Thr of the $\beta 2$ subunit. Moreover, this newly developed substrate is, to our knowledge, one of the best substrates designed for the $\beta 2$ subunit of the $20 S$ proteasome. The majority of substrates in the proteasome assay required the presence of SDS as an artificial activator in the system. Substrate 1 could be used without such an addition, making the assay much simpler to perform. Using our substrate, we detected 20S proteasome activity in the human urine samples from bladder cancer patients. This observation could be useful for the noninvasive diagnosis of this severe disease.

Author Contributions: Conceptualization, A.L. and M.W.; methodology, M.W., A.L. and A.G.; investigation, M.W., N.G., A.R., M.M. and A.G.; resources, M.W. and A.L.; data curation, M.W., N.G., A.R., M.M. and A.G.; writing-original draft preparation, M.W., A.L. and A.G.; writing-review and editing, M.W., A.L. and A.G.; visualization, M.W., A.L. and A.G.; supervision, A.L. and M.W.; funding acquisition, M.W. All authors read and agreed to the published version of the manuscript.

Funding: This work was supported by the National Science Center Poland under grant no. UMO-2017/27/B/ST5/02061 (MW).

Conflicts of Interest: The authors declare no conflicts of interest. The funders had no role in the design of the study; in the collection, analyses, or interpretation of data; in the writing of the manuscript, or in the decision to publish the results.

\section{References}

1. Groll, M.; Ditzel, L.; Leowe, J.; Stock, D.; Bochtler, M.; Bartunik, H.D.; Huber, R. Structure of 20 S proteasome from yeast at $2.4 \AA$ resolution. Nature 1997, 386, 463-471. [CrossRef] [PubMed]

2. Tanaka, K.; Mizushima, T.; Saeki, Y. The proteasome: Molecular machinery and pathophysiological roles. Biol. Chem. 2012, 393, 217-234. [CrossRef] [PubMed] 
3. Jeager, S.; Groll, M.; Huber, R.; Wolf, D.H.; Heinemeyer, W. Proteasome $\beta$-type subunits: Unequal roles of propeptides in core particle maturation and a hierarchy of active site function. J. Mol. Biol. 1999, 291, 997-1013. [CrossRef] [PubMed]

4. Dick, L.R.; Cruikshank, A.A.; Grenier, L.; Melandri, F.D.; Nunes, S.L.; Stein, R.L. Mechanistic studies on the inactivation of the proteasome by lactacystin: A central role for clastolactacystin $\beta$-lactone. Biochemistry 1996, 35, 899-908.

5. Borissenko, L.; Groll, M. Diversity of proteasomal missions: Fine tuning of the immune response. Biol. Chem. 2007, 388, 947-955. [CrossRef]

6. Groll, M.; Heinemeyer, W.; Jeager, S.; Ullrich, T.; Bochtler, M.; Wolf, D.H.; Huber, R. The catalytic sites of $20 \mathrm{~S}$ proteasomes and their role in subunit maturation: A mutational and crystallographic study. Proc. Natl. Acad. Sci. USA 1999, 96, 10976-10983. [CrossRef]

7. $\quad$ Egerer, K.; Kuckelkorn, U.; Rudolph, P.E.; Rückert, J.C.; Dörner, T.; Burmester, G.R.; Kloetzel, P.M.; Feist, E. Circulating proteasomes are markers of cell damage and immunologic activity in autoimmune diseases. J. Rheumatol. 2002, 29, 2045-2052.

8. Majetschak, M.; Perez, M.; Sorell, L.T.; Lam, J.; Maldonado, M.E.; Hoffman, R.W. Circulating $20 \mathrm{~S}$ proteasome levels in patients with mixed connective tissue disease and systemic lupus erythematosus. Clin. Vaccine Immunol. 2008, 15, 1489-1493. [CrossRef]

9. Sixt, S.U.; Dahlmann, B. Extracellular, circulating proteasomes and ubiquitin-Incidence and relevance. Biochim. Biophys. Acta 2008, 1782, 817-823. [CrossRef]

10. Hoffmann, O.; Heubner, M.; Anlasik, T.; Winterhalter, M.; Dahlmann, B.; Kasimir-Bauer, S.; Kimmig, R.; Wohlschlaeger, J.; Sixt, S.U. Circulating $20 \mathrm{~S}$ proteasome in patients with non-metastasized breast cancer. Anticancer Res. 2011, 31, 2197-2201.

11. Xinghua, W.; Weiwe, Z.; Xie, K.; Diao, P.; Tang, P. Potential use of chymotrypsin-like proteasomal activity as a biomarker for prostate cancer. Onc. Let. 2018, 15, 5149-5154.

12. Kakurina, G.V.; Cheremisina, O.V.; Choinzonov, E.L.; Kondakova, I.V. Circulating Proteasomes in the Pathogenesis of Head and Neck Squamous Cell Carcinoma. Bull. Exp. Biol. Med. 2017, 163, 92-94. [CrossRef] [PubMed]

13. Heubner, M.; Wimberger, P.; Dahlmann, B.; Kasimir-Bauer, S.; Kimmig, R.; Peters, J.; Wohlschlaeger, J.; Sixt, S.U. The prognostic impact of circulating proteasome concentrations in patients with epithelial ovarian cancer. Gynecol. Oncol. 2011, 120, 233-238. [CrossRef] [PubMed]

14. Romaniuk, W.; Kalita, J.; Ostrowska, H.; Kloczko, J. Proteasome $20 \mathrm{~S}$ in multiple myeloma: Comparison of concentration and chymotrypsin-like activity in plasma and serum. Scand. J. Clin. Lab. Invest. 2018, 78, 253-257. [CrossRef]

15. Jakob, C.; Egerer, K.; Liebisch, P.; Türkmen, S.; Zavrski, I.; Kuckelkorn, U.; Heider, U.; Kaiser, M.; Fleissner, C.; Sterz, J.; et al. Circulating proteasome levels are an independent prognostic factor for survival in multiple myeloma. Blood 2007, 109, 2100-2105. [CrossRef]

16. Harris, J.L.; Alper, P.B.; Li, J.; Rechsteiner, M.; Backes, B.J. Substrate specificity of the human proteasome. Chem. Biol. 2001, 8, 1131-1141. [CrossRef]

17. Nazif, T.; Bogyo, M. Global analysis of proteasomal substrate specificity using positional-scanning libraries of covalent inhibitors. Proc. Natl. Acad. Sci. USA 2001, 98, 2967-2972. [CrossRef]

18. Rut, W.; Poręba, M.; Kasperkiewicz, P.; Snipas, S.J.; Drag, M. Selective substrates and activity-based probes for imaging of the human constitutive $20 \mathrm{~S}$ proteasome in cells and blood samples. J. Med. Chem. 2018, 61, 5222-5234. [CrossRef]

19. Wysocka, M.; Gruba, N.; Grzywa, R.; Giełdoń, A.; Bąchor, R.; Brzozowski, K.; Sieńczyk, M.; Jenne, D.; Szewczuk, Z.; Rolka, K.; et al. PEGylated substrates of NSP4 protease: A tool to study protease specificity. Sci. Rep. 2016, 6, 22856. [CrossRef]

20. Van der Linden, W.A.; Willems, L.I.; Shabaneh, T.B.; Li, N.; Ruben, M.; Florea, B.I.; van der Marel, G.A.; Kaiser, M.; Kisselev, A.F.; Overkleeft, H.S. Discovery of a potent and highly $\beta 1$ specific proteasome inhibitor from a focused library of urea-containing peptide vinyl sulfones and peptide epoxyketones. Org. Biomol. Chem. 2012, 10, 181-194. [CrossRef]

21. Gruba, N.; Wysocka, M.; Brzezinska, M.; Dębowski, D.; Sienczyk, M.; Gorodkiewicz, E.; Guszcz, T.; Czaplewski, C.; Rolka, K.; Lesner, A. Bladder cancer detection using a peptide substrate of the $20 \mathrm{~S}$ proteasome. FEBS J. 2016, 283, 2929-2948. [CrossRef] 
22. Kisselev, A.F.; Goldberg, A.L. Monitoring activity and inhibition of $26 \mathrm{~S}$ proteasomes with fluorogenic peptide substrates. Methods Enzymol. 2005, 398, 364.

23. Arshbarger, W.; Miller, C.; Diedrich, C.; Sacchettini, J. Crystal structure of the human $20 \mathrm{~S}$ proteasome in complex with carfilzomib. Structure 2015, 23, 418-424. [CrossRef] [PubMed]

24. Korb, O.; Stützle, T.; Exner, T.E. Empirical scoring functions for advanced protein-ligand docking with PLANTS. J. Chem. Inf. Model. 2009, 49, 84-96. [CrossRef] [PubMed]

25. Wysocka, M.; Lesner, A.; Gruba, N.; Korkmaz, B.; Gauthier, F.; Kitamatsu, M.; Łegowska, A.; Rolka, K. Three wavelength substrate system of neutrophil serine proteinases. Anal. Chem. 2012, 84, 7241-7248. [CrossRef] [PubMed]

26. Furka, A.; Sebestyen, F.; Asgedom, M.; Dibo, G. General method for rapid synthesis of multicomponent peptide mixtures. Int. J. Pept. Protein Res. 1991, 37, 487-493. [CrossRef]

27. Houghten, R.A.; Pinilla, C.; Blondelle, S.E.; Appel, J.R.; Dooley, C.T.; Cuervo, J.H. Generation and use of synthetic peptide combinatorial libraries for basic research and drug discovery. Nature 1991, 354, 84-86. [CrossRef]

28. Wysocka, M.; Sychowska, K.; Gruba, N.; Winiarski, Ł.; Skoreński, M.; Psurski, M.; Makowska, J.; Giełdoń, A.; Wenta, T.; Jarząb, M.; et al. Selection of effective HTRA3 activators using combinatorial chemistry. A.C.S Comb. Sci. 2017, 19, 565-573. [CrossRef]

(C) 2020 by the authors. Licensee MDPI, Basel, Switzerland. This article is an open access article distributed under the terms and conditions of the Creative Commons Attribution (CC BY) license (http://creativecommons.org/licenses/by/4.0/). 